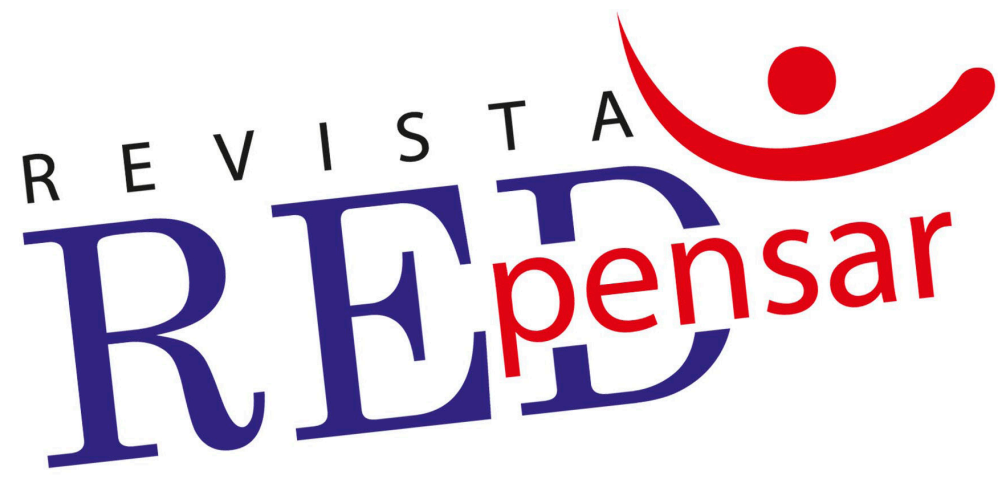

\title{
Un cuento para creer en las transformaciones educativas
} A story to believe in educational transformations

\section{Erika Paola Motta Totena}

Revista REDpensar, volumen 6, número 1, Ene-Jun 2017

ISSNe: 2215-5384

Revelando otras prácticas 3 Recibido: 22 de marzo del 2018 Aceptado: 05 de mayo del 2018

DOI: 10.31906/redpensar.v6i1.131

\section{(ㅇ)(1) $\$(0)$}




\title{
Un cuento para creer en las transformaciones educativas
}

\author{
A story to believe in educational transformations
}

Erika Paola Motta Totena ${ }^{1}$

\section{Resumen}

La historia nos ha mostrado que los arquetipos siempre serán los mismos, nunca hemos intentado ir más allá de esas versiones, por ello cuando somos perturbadores y capaces de incitar en los niños y las niñas la búsqueda de nuevas versiones y exégesis, estamos dando el primer paso para fomentar otras visiones. Cuando les sumergimos en la literatura y en la educación damos a conocer un mundo cubierto de secretos, posibilidades y emociones, les abrimos la puerta de la incertidumbre e inquietud. Eso es precisamente lo que sucede en este relato, donde algunas consideraciones rígidas y estáticas, pueden ser transformadas si leemos con nuevos ojos, a partir de la interiorización de los conceptos presentados por Denisse Najmanovich, Francisco Gutiérrez, Cruz Prado, Leonardo Boff y Rose Muraro.

Palabras Clave: BIOPEDAGOGÍA, COMPLEJIDAD, EMOCIÓN, LITERATURA, REDUCCIONISMO.

\section{Abstract}

History has shown us that the archetypes will always be the same, we have never tried to go beyond those versions, so when we are disturbing and able to incite in children the search for new versions and exegesis, we are giving the first step to encourage other minions, so when we dive from education and literature to a world covered in secrets, possibilities and emotions we are opening the door of uncertainty, letting them think of other possibilities; that is precisely what happens in this story where some rigid and static considerations can be transformed if we read with new eyes, from the interiorization of the concepts presented by Denisse Najmanovich, Francisco Gutiérrez, Cruz Prado, Leonardo Boff and Rose Muraro.

Keywords: BIOPEDAGOGY, COMPLEXITY, EMOTION, LITERATURE, REDUCTIONISM.

\footnotetext{
1. Licenciada en Lengua Castellana-Universidad del Tolima. Especialista en Pedagogía. Magíster en Educación- Universidad del Tolima. Docente Catedrática del Instituto de Educación a Distancia (IDEAD) - Universidad del Tolima. Docente de la Secretaría de Educación de Ibagué - Tutora del Programa “Todos a Aprender”. Correo electrónico:paomotta02@,hotmail.com
} 
Relatan los abuelos y las abuelas que existió una bruja muy particular, no era la típica dama de los cuentos fantásticos; llena de verrugas, con nariz puntiaguda, dientes disparejos, sombrero picudo, escoba voladora, traje oscuro, con piel arrugada y ajada, tampoco hacía encantamientos malignos, ni mucho menos envenenaba manzanas, era realmente una especie de bruja en extinción. Nadie tenía seguridad sobre cuál era su origen, al parecer ninguna historia hablaba de ella, por eso era tan poco conocida, pues ni en Blanca Nieves estaba, ni en la Bella Durmiente, menos en Hansel y Gretel y definitivamente en Rapunzel tampoco, entonces ¿Quién era esta misteriosa Bruja?, era la pregunta que rodaba de reino en reino, muchos pensaban que si esta era una bruja diferente a las otras, en definitiva no era una bruja, sino que debía ser una hada mágica; idea que tampoco era cierta, pues no tenía una varita, ni alas diminutas para volar o un vestido resplandeciente.

Poco se sabía de ella, se decía que tenía dos amigas incondicionales: Biopedagogía y Literatura, ellas ni brujas ni hadas eran, solo unas incondicionales aprendientes; sin duda, ellas no solamente se consideraban confidentes de la Bruja, cuyo nombre era Emoción, sino que compartían con todos los seres del bosque de la certidumbre, un lugar donde las diferencias y las dudas eran poco apetecidas; por ello sabían que la gran mayoría de pobladores experimentaban temor por la divergencia de aquella Bruja sin descripción, pues no podían definirla en un grupo específico y eso sí que era muy difícil, pues desde pequeños y pequeñas estaban acostumbrados a clasificar los objetos, las personas y los sentimientos.

Cierta mañana, cuando estaban realizando una de las actividades que más les gustaba; la pintura de flores de cambio, llegó una carta del cabildo de brujas, todas se sorprendieron, y más aún cuando el mensajero, les dijo: -"su actitud está cambiando nuestras reglas, deberían de reconsiderarlas, no se salgan de los límites, solo existe una visión para todas las cosas", y no olviden mi nombre: soy Reduccionismo.

A lo cual Biopedagogía dijo:

- No te preocupes, todos y todas tenemos el derecho y la libertad de percibir y contemplar de diversas formas.
Mientras que Literatura por su parte, afirmó:

- Los paradigmas pueden variar, ser fijo e inamovible no es la solución, en el holismo y la complejidad muchas cosas se pueden encontrar y preguntar.

Tras unos minutos de reflexión, Literatura le sugirió a aquella Bruja que se mirara en el espejo, intentando describirse. Biopedagogía la observaba fijamente, sin pronunciar ni un sonido, reconociendo que cada Otredad hace parte de la naturaleza, que la esencia no está en la estandarización, sino en el devenir y en las interacciones. De manera intuitiva, aquella mujer radiante, realizó un acoplamiento estructural, se vio a sí misma, se adentró más allá de su vestido corporal, se sintió libre, sus células danzaron y sus horizontes se ensancharon. De pronto su existencia se reconfiguró, tomando valor y flexibilidad para leer aquello que su corazón ya sabía.

Suavemente abrieron la carta, la cual decía: Estimada Hermana Bruja,

Lamentamos tener que escribir esta nota, pero estamos profundamente preocupadas, hasta los rincones del mundo de la educación infantil ha llegado el rumor, que eres diferente, debido a que rompes los esquemas tradicionales, eres inexplicablemente una bruja no bruja, eso nos ha ocasionado grandes problemas, pues no podemos clasificarte como bruja, pero tampoco como una de nuestras adversarias; las hadas, te pedimos que abandones estas tierras, y busques un lugar donde puedas encajar. Sin otro particular, nos despedimos. Posdata: Si deseas continuar aquí, debes cumplir con nuestros prototipos.

Para ese momento las palabras sobraron, un fuerte abrazo de sus compañeras incondicionales, fue su aliciente, la dicotomía entre ser bella o fea, buena o mala, dulce o amarga, aceptada o rechazada, se convirtió en la única alternativa. Entonces decidieron hacer un listado de las características de cada uno de los tipos de brujas que conocían, las buenas y las malas, para ello le pidieron ayuda a todas y todos las habitantes del Bosque de la Certidumbre, fue así como cada uno aportó las ideas relacionadas con la misión, definiendo que la mayoría de brujas debían ser: 
estáticas, enemigas de los cambios, silenciosas y dogmáticas.

Tras el resultado, Emoción se sintió muy decepcionada, pues ella no tenía esas cualidades, además tampoco creía que una bruja deber ser maligna o benigna, simplemente que era un ser vivo con fortalezas, destrezas y aspectos por mejorar, entonces decidió irse de aquel Bosque, en busca de un lugar donde existieran nuevas concepciones; caminó durante varios días, conoció múltiples lugares, en muchos de estos fue expulsada, en otros meramente aprobada, hasta que finalmente llegó al Bosque de la Fluidez, allí encontró un universo infinitamente diverso, lleno de incógnitas, comprensión y miradas inmanentes e implicadas.

$\mathrm{Al}$ recorrer algunos de sus espacios, una voz contundente le dijo: "nuestra experiencia no es individual ni pasiva, sino culturalmente moldeada, corporalmente encarnada y colectivamente construida" (Najmanovich, 2016) así que no tienes que preocuparte, debes empezar por despojarte de esos calificativos, tu nombre es y seguirá siendo Emoción, lo de bruja o hada no debe determinar tu futuro o tus acciones. Al escuchar esas palabras enormemente cautivadoras, todo su ser sintió vibraciones especiales; sus sentidos se agudizaron, sus preceptos dieron un giro de $180^{\circ}$ grados, dándose cuenta que los imaginarios son siempre cambiantes, lo importante es formar parte de esa variación.

Sin embargo, algo en su interior aún estaba inquieto, ¿de quién sería aquella voz que logró perturbar sus creencias?, con cierto temor intentó preguntarle, evitando ser impertinente o inadecuada, la respuesta hallada fue sorprendente, aquella melodiosa voz era de alguien llamada Complejidad, recordó rápidamente que esa palabra ya la había escuchado a través de Biopedagogía, su añorada amiga. Dándole las gracias, partió a toda velocidad, tenía que contarle a los seres del Bosque Certidumbre, a las Brujas del Consejo y sobre todo a sus compañeras, aquello que había descubierto.

Durante su travesía encontró muchos libros, cada uno contenía la historia de una hechicera en particular, así que antes de llegar a su destino, emprendió la exploración de aquellos relatos, fue así como llegó donde aquella que todos culpaban de envenenar las manzanas, al

verla percibió en sus gestos, que era un gran ser.
Indiscutiblemente, aquella fama de maléfica no era más que una confusión, pues realmente lo que hizo esa bruja fue caramelizar con panela y azúcar una deliciosa fruta, sin jamás imaginar que aquella princesa fuera alérgica al dulce, así lo supo porque ella misma se lo explicó, dándole como obsequio la poma más jugosa y suave, que nunca antes había probado.

Más adelante y en medio de dulces, golosinas y capas rojas, otra simpática bruja se halló, preguntándole si ella era la que el mundo conocía por devorar infantes, a lo cual respondió rotundamente:

- No, ya que no soy la misma de años atrás, pues la visita de una pequeña llamada Intuición, todo eso me permitió cambiar, ahora mis dulces y chocolatinas son fuente de inspiración, regalándole bombones y galletas, eso comprobó. Kilómetros hacia el norte y estando a punto de llegar al Bosque Certidumbre, las ruinas de una gran torre pudo divisar, allí las huellas de niños y niñas pudo palpar, sintiendo en sus hombros una suave mano, que le dijo:

- Bienvenida, antiguamente en este sitio estaba ubicado un lugar de represión, pero gracias al amor, las vinculaciones y al diálogo esto terminó. Los dorados cabellos de mi querida Rapunzel ahora se mecen sin cesar con la suave brisa de este renovado lugar, una transformación que debería darse desde todas las esferas de la educación, ese es el ideal esperanzador para el Siglo XXI, añadiendo a esto que éstas vinculaciones deben ser "placenteras, gratificantes y satisfactorias" (Prado y Gutiérrez, 2004, p.39).

Con gratitud profunda, recorrió los pocos metros que la separaban de su hogar, recordando paso a paso los testimonios de aquellas que llamaban brujas, mientras lo hacía Biopedagogía y Literatura, la recibieron con Visión Plurisémica, una nueva habitante del Bosque. Ella detenidamente, les contó acerca del encuentro con Complejidad, sobre los obsequios y sobre las concepciones que se esconden en cada relato literario, le dio un gran abrazo de bienvenida a la nueva integrante, comprendiendo que su búsqueda había sido fructífera. Al caer la noche, Bruja Emoción, tomó un descanso, para prepararse interiormente para ir a la mañana siguiente donde las Brujas de la Asamblea.

Como era de esperarse en la puerta estaban el mensajero Reduccionista y el guardián Objetivismo, 
quienes le impedían a toda costa pasar, solo mediante gritos y la intercepción de Subjetividad pudo entrar; al principio ninguna de ellas quería escucharla, pues eran muy rígidas sus normas y no existía modo de cambiarlas, tras contarles lo sucedido y al entregarles un trozo de manzana, bombones y galletas sus paladares se innovaron, sus pieles se erizaron y sus imaginaciones se expandieron, pues sin darse cuenta el campo Akásico alimento sus visiones y concepciones, aquellas agrias y déspotas brujas, sintieron como florecía su aura, comprendieron que nadie es totalmente blanco o negro, sino que los colores y sus destellos viven dentro de cada una, que la Incertidumbre debe ser parte y arte de la vida, dejando de lado ese momento en que "La humanidad pasó de la conciencia de solidaridad a la conciencia de competición" (Boff y Muraro, 2004, p. 12).

Todas parecían muy felices, al haber entendido el mensaje, pero la Bruja más antigua de la corte llamada Comprobación llegó a aquel lugar, todas pensaron que iba a hacer lo suyo, pero por el contrario decretó que no todo estaba dicho, que al igual que los caminos de Caperucita y el lobo, existen bifurcaciones que llevan a distintos aprendizajes, a cambios integrales, modificando lo viejo a través de nuevas experiencias, diciendo:
- Me siento rebosante de alegría al darme cuenta de que podía cambiar el curso de mi vida mediante el simple hecho de cambiar mis creencias. (Lipton, 2005. p. 9)

Al escucharla todos y todas sorprendidos y sorprendidas no necesitaron comprobar, solo sintieron que las diferencias están en los ojos del que observa, en sus prejuicios, porque lo realmente esencial no es superficial; la inocencia de los representantes de la niñez permanece a través del tiempo. Desde ese día, los cuentos han cambiado las visiones de mundo, las lecturas se han vuelto cada vez más polifónicas y la literatura sigue siendo como siempre una verdadera tejedora de mundos sensibles y posibles.

Se trata entonces de aprender con la vida y las relaciones que subyacen a las realidades escolares y educativas, especialmente la de este siglo, de allí que una de las estrategias pedagógicas y didácticas sea leer con nuevos ojos, pensar de otras maneras, abrir los libros de historias, cuentos y relatos para reinterpretarlos, no solo con visos moralistas, sino con emociones facilitadoras de cambios como los de las diversas brujas que rompieron los esquemas que nos habían planteado, leyendo desde todas las formas posibles.

\section{Referencias Bibliográficas}

Boff, L. y Muraro, R. M. (2004). Femenino y Masculino. Madrid, España: Editorial Trotta.

Gutiérrez, F. y Prado, C. (2004). Germinando Humanidad: Pedagogía del aprendizaje. Guatemala: Save the Children-Noruega.

Lipton, B. (2005). La biología de la Creencia: La liberación del poder de la conciencia, la materia y los milagros. Madrid, España: Editorial Palmyra.

Najmanovich, D. (2016). Los enfoques de la complejidad. Argentina: Seminario virtual. Recuperado de https://goo.gl/p5GMYC 